\title{
Review of Interaction and Second Language Development: A Vygotskian perspective
}

\author{
Kadriye Aksoy a * (D) \\ ${ }^{a}$ Canakkale Onsekiz Mart University, Anafartalar Kampusu, Canakkale, Turkey
}

Received 19 July 2017 | Received in revised form 3 March 2018 | Accepted 24 March 2018

\begin{abstract}
Interaction and Second Language Development: A Vygotskian perspective, Remi Adam van Compernolle. John Benjamins Publishing Company (2015). 213 pp. ISBN: 978-90-272-1331-0 (PB)

(C) 2018 EJAL \& the Authors. Published by Eurasian Journal of Applied Linguistics (EJAL). This is an open-access article distributed under the terms and conditions of the Creative Commons Attribution license (CC BY-NC-ND) (http://creativecommons.org/licenses/by-nc-nd/4.0/).
\end{abstract}

Keywords: sociocultural theory; interaction; language development.

Sociocultural theory (SCT), also known as cultural-historical psychology (Vygotsky, 1978, 1986), sees language and communicative interaction play an important role in helping language learners develop or mediate higher psychological functions such as learning. So, researchers who take up SCT as their research paradigm follow a critical perspective on the quality of interactions between teachers and learners or among learners to find out how interaction helps or mediates second language (L2) development. By writing the book, van Compernolle aims to provide a clear picture to show the interplay between interaction and L2 development from a Vygotskian perspective. The book is divided into eight chapters, in each of which a key theoretical issue in L2 interaction from SCT perspective is discussed, exemplified by excerpts from different types of data and made relevant to language pedagogy.

The author starts with an introductory chapter to provide a sketch of different perspectives on the role of interaction in the domain of L2 development, and he then moves to illustrate the place of interaction in Vygotskian sociocultural theory. $\mathrm{He}$ briefly provides the history of the development of the interactionist approaches starting from Long's (1981) interaction hypothesis, to Swain's (1985) pushed output and other related concepts (e.g. negotiation for meaning, uptake) within the interactionist approach. He criticizes both weak and strong perspectives of interactionist perspectives arguing that they lack explaining cognition and context together. For him, Vygotskian SCT provides a powerful framework in which the internal-psychological and the external-social are brought together (p.6). Moreover,

\footnotetext{
* Corresponding author name.

E-mail address: kadriyeaksoy@yahoo.com

http://dx.doi.org/...
} 
he also suggests that SCT and strong socio-interactionist approaches can complement each other to produce a robust theoretical and empirical account of L2 development in social interaction.

In chapter 2, the author introduces readers with the key concepts of SCT in relation to social interaction and L2 development such as mediation, the place of communicative interaction, internalization, zone of proximal development (ZPD), the relation between learning, development and instruction. He then discusses microdiscourse analysis as an approach to analyze interaction and L2 development. For him, taking an emic perspective, as in conversation analysis (CA), provides a powerful tool to analyze moment-to-moment sequential organization of interactions and to show how microinteractional features of talk and non-linguistic semiotic fields are integrated into and mediate interaction (p.22). He exemplifies his position with an excerpt transcribed in three different ways in order to point the power of detailed transcription by referring to Vygotsky's (1978) notion of grasping the process in flight. Based on these SCT-driven concepts, he concludes that since L2 development involves the internalization of language as a mediational tool, SCT-driven L2 pedagogy should take the basis of helping learners appropriate the patterns of meaning in the L2, and accordingly, L2 communicative tasks should focus primarily on developing learners' control over meanings rather than forms. Also, during communicative interaction, these tasks can construct a ZPD in which learners are provided support by more experts (teachers, peers). From the perspective of SCT, this support should be graduated and contingent (Aljaafreh \& Lantolf, 1994) which means providing enough assistance for success without over-assisting. Lastly, the author suggests that teachers can have an awareness of interactional practices by doing a detailed transcription of their own classroom interactions. This helps teachers find out in which situations they should intervene in learners' interactions.

In the following chapter, van Compernolle further explores how communicative interaction is the primary source and triggers developmental processes from the SCT perspective, and the reflections of these views on L2 research. Firstly, he distinguishes how SCT differs from cognitivist psychological theories in its view of L2 development by referring to the concept of internalization, and refers to the conceptualization of interaction as joint activity. He then moves to the most famous concepts of SCT such as scaffolding and mediation; and by providing examples, he clearly illustrates the differences between these concepts as they occur in communicative interaction. In the remaining of the chapter, he focuses on how L2 SCT research identifies and explains the processes by which L2 abilities emerge. By referring to genetic development of L2 abilities, he investigates the importance of linking conscious knowledge of language to performance, and the place of imitation in internalization. He then goes on to investigate the growth of conscious L2 knowledge by addressing two contexts (e.g. meaning-focused tasks and collaborative awarenessraising tasks) in which such development may occur. As a pedagogical implication, he advises language teachers to design interactive tasks to support learners in 
developing their capacities to deploy L2 forms based on a conscious understanding of the meaning.

In the fourth chapter, the author investigates negotiation for meaning from the perspective of SCT, focusing on primarily co-regulation, mediation sequences and incidental microgenesis. One focus of L2 SCT research on interaction is on how one person can regulate the other person's actions through communication. During the regulation process, neither agency nor passiveness is given to either party of the interactants since both parties have an influence on each other's actions. He defines this process as having a co-regulation which is defined a dialogic process involving the contribution of all participants during communicative interaction, including 'mediated joint activity' in order to maintain intersubjectivity (p.65). During some instances, interactants may need to negotiate appropriate forms of support due to some L2 problems such as lack of vocabulary knowledge or grammatical competence. He then mentions mediation sequences inserted during communicative interaction as selfinitiated and other-initiated either in implicit or explicit forms. The author values those sequences because of their use of microgenetic analysis. In the last part of the chapter, he describes incidental microgenesis by specifically referring to the one mediated by repair. He also argues that language learning tasks, which help microgenetic development, also provide learners interactionally relevant items to pick up and recycle in their own utterances (p.82).

In the fifth chapter, van Compernolle discusses the role of L1 interaction in L2 development. By referring to Macaro (2009), he argues that an optimal use of L1 can support L2 development. Similarly, SCT also supports this idea since the use of L1 can be a psychological tool to mediate the internalization of L2 development. By examining L1 collaborative dialogue that happens during L2 tasks, he provides supportive findings for his argument. He also suggests that this type of interactions can have both intrapersonal and interpersonal functions during L2 tasks by referring to previous SCT-informed research. What follows is that he, in a nutshell, focuses on concept-based instruction which is a particular type of pedagogy grounded in SCT and refers to the use of L1 for L2 metalinguistic development. The studies conducted by him and his colleagues on either the development of sociopragmatics in L2 French or focus and declension in L2 German clearly show that the use of L1 can be a more powerful tool to promote metalinguistic development. He provides two considerations for teachers to think about the mediating role of L1 during L2 communication. The first one is when L1 use serves as a metacommunicative function during which learners use L1 to plan, evaluate, learn about L2 communicative activity. Through this, L2 development is supported since learners can expand their L2 resources by using L1. Teachers should be aware of this metacommunicative function especially for when L1 is required as cognitive resource to accomplish an L2 task. Another consideration is the learners' level of ability to engage in cognitive activities in the L2. For example, it would be a waste of time to ask elementary level learners to engage in complex, abstract thinking through the use of L2 if the learners are not able to use L2 
to regulate their mental activity (p.108). However, with more advanced level of learners, it would be possible to use L2 to mediate L2 development.

In the next chapter, the author examines the roles of participation and active reception in L2 development. He firstly defines the terms, and then argues their relation to L2 development within SCT. He refers to Goodwin's (2007) interactive footing which is the extension frameword of Goffman's (1981) concept of footing which originally means positioning of interactants vis-à-vis their interlocutors and divides interactants' roles into speakers and hearers. Interactive footing refers to the ways how participant roles are oriented to, shaped by one another through different resources. These included linguistic resources, nonverbal behaviours and the environment of the interaction. According to Goodwin (2007), roles are dynamic and change through the previously mentioned resources. Van Compernolle clearly shows how footing is involved in mediation and facilitates internalization for L2 development by two interactive situations. He then moves on to mention how learners become active agents to appropriate environmental resources for the development of L2 patterns of meaning and language. He also shows how language forms and language meaning can be mediated and recycled during L2 conversations. Through the end of the chapter, he focuses on participation and active reception, which involves a person's active engagement in attending to talk-in-interaction, mediational tools which are present in the environment, in the context of interpersonal activity. He clearly illustrates the roles of self-directed talk and non-verbal communication such as eye gaze, body posture, and gesture in private speech. Lastly, he advises teachers to be aware of using various resources including language, gestures, and objects in their environment and how students orient to those resources for their language development. He further suggests that teachers be sensitive to various types of participation in the classroom, which also involves active reception, and construct ways for learners to develop their skills. Teachers, for example, can encourage learners to engage in vicarious responses or private speech or languaging which are the ways that help engage in active reception.

In the seventh chapter, van Compernolle focuses on the relationship between interaction and L2 development within dynamic assessment (DA). He explains that DA is an approach to evaluating what a learner can do independently and what the learner can achieve with the help of a mediator. So, assessment ad teaching are seen as an integrated activity of diagnosis through intervention (Poehner \& van Compernolle, 2011). He informs the readers about the approaches to support learners in DA such as interactionist DA and interventionist DA (Lantolf \& Poehner, 2004). He also cautions the readers that these two approaches are not very distinct from each other, but they differ in terms of ends of a continuum of strategies for mediating learner performance. He exemplifies two approaches with clear explanations and interaction scenarios. He then goes on to focus on two types of assessment tasks; namely, communicative tasks and language tests. He provides examples for each type of tasks and also touches upon the relationship between the mediator and the learner during these exchanges. After these, he moves to two distinct frames of interaction in 
which mediation occurs: collaborative frame and cooperative frame. First, he looks at them, and then he mentions the interplay between these frames. He emphasizes that these frames are not very distinct types to mediation; but rather, they have different orientations to the object of mediation. He again refers to DA's being a unity of diagnostic and developmental activity. Lastly, he provides teachers with alternatives about how to employ DA in the context of formal setting and as an approach in classroom-based assessment. For formal assessment, he advises to develop a rubric that includes not only solo performances but also with teacher support. For classroombased assessment, concurrent or cumulative DA can be employed in regard to curricular goals.

The author, in the eighth chapter, focuses on interactional competence from the perspective of SCT, opposing to the previous notions of competence that see language knowledge as residing in the individual; but to the contrary, it is a joint activity in which coparticipants orient to as appropriate and relevant in a given interaction (p.171). Based on Rine's (2009) discussion, he provides five dimensions of interactional competence and a relevant interaction scenario to exemplify these dimensions in a vocabulary review lesson between a teacher and students. He shows how interactional competencies become available in interaction in two different ways and demonstrates how these ways are reflected in interaction. He then moves to the mediational role between interactional competence and L2 development. He mentions interactional competencies mediate L2 development in some ways, and these are referred as interactional resources used as means for internalizing psychological mediators such as self-regulatory practices, L2 concepts, grammatical constructions, and so on (p.179). He also shows how L2 development mediates interactional competence in that the internalization of L2 interactional resources expands learner's repertoire of means for successful interaction. He later takes the readers' attention to Walsh's (2006) classroom interactional competence. Although it is coconstructed between teacher and learners, he separately focuses on a teacher's use of interactional resources for mediating students' learning during a review of a reading comprehension assignment with a small group and how two learners deploy relevant resources during this exchange. Lastly, he emphasizes the importance of developing interactional competence both by teachers and learners. To accomplish this, by referring to Walsh (2011), he advises teachers to analyze their own practices through video recordings. In a similar vein, learners can be asked to analyze interactions with the help of a rubric developed in accordance with Rine's division of interactional competence.

In the concluding chapter, van Compernolle first emphasizes SCT's division from cognitivist-interactionist and strong-interactionist perspectives. He summarizes the key points of SCT which are relevant to understanding human interaction discussed in the previous chapters. Then, he provides implications for further research in the domain of SCT such as the orientations of L2 learners to learning objects (Markee, 2008) or the role of imitation, private speech in relation to learning objects. Also, although interactional competence is widely researched by conversation analytic perspective, there are few attempts to understand how interactional competence 
shape and is shaped by participation in sociocultural activity. Regarding pedagogy, he puts forward that one aim of L2 teaching is to mediate the internalization of new stimuli through interaction. It is also advised to evaluate classroom interactional competence through the use of video recordings. As a final comment, he says that L2 development is a process incorporating language, body, participants and tools as a holistic system. Therefore, the goal should be to understand this within SCT.

In the final analysis, I should say that I really enjoyed reading such a simplified, to the point book related to SCT and also learned a lot from the book. Some of the key concepts related to SCT might be complicated. However, with its down-to-earth explanations and clear examples from actual interactions, van Compernolle successfully provides a clear picture of SCT research paradigm. In addition, the exercises provided at the end of each chapter make reading the book more fun and help readers practice the issues outlined in each chapter. I can, therefore, recommend the book to the researchers who take up SCT as their research paradigm like me, L2 teachers and learners for a more effective L2 environment.

\section{Acknowledgements}

I would like to express my gratitude to my supervisor, Prof. Dr. İsmail Hakkı ERTEN, for giving me the chance to write a review of this book. I also would like to thank to the publishing house for sending me an inspection copy of the book.

\section{References}

Aljaafreh, A., \& Lantolf, J.P. (1994). Negative feedback as regulation and second language learning in the zone of proximal development. Modern Language Journal, 78, 465-483. doi:10.1111/j.1540-4781.1994.tb02064.x

Goffman, E. (1981). Forms of talk. Philadelphia, PA: University of Pennsylvania Press.

Goodwin, C. (2007). Participation, stance and affect in the organization of activities. Discourse and Society, 18, 53-73. doi: 10.1177/0957926507069457

Lantolf, J. P. \& Poehner, M. E. (2004). Dynamic assessment of L2 development: Bringing the past into the future. Journal of Applied Linguistics, 1(1), 49-74. DOI: 10.1558/japl.v1i1.49

Long, M. (1981). Input, interaction, and second-language acquisition. Annals of the New York Academy of Sciences, 379, 259-278. doi: 10.1111/j.1749-6632.1981.tb42014.x.

Macaro, E. (2009). Teacher use of code-switching in the L2 classroom: Exploring 'optimal' use. In M. Turnbull \& J. Dailey-O'Cain (Eds.), First language use in second and foreign language learning (pp. 35-49). Clevedon: Multilingual Matters.

Markee, N. (2008). Toward a learning behavior tracking methodology for CA-for-SLA. Applied Linguistics, 29(3), 404-427. DOI: https://doi.org/10.1093/applin/amm052

Poehner, M.E. \& van Compernolle, R.A. (2011). Frames of interaction in dynamic assessment: Developmental diagnoses of second language learning. In M.E. Poehner \& P. Rae-Dickens (Eds.), Addressing issues of access and fairness in education through dynamic assessment [Special Issue]. Assessment in Education: Principles, Policy and Practice, 18(2), 183-198. 
Rine, E.F. (2009). Development in dialogic teaching skills: A micro-analytic case study of a pre-service ITA. Unpublished dissertation, The Pennsylvania State University, University Park.

Swain, M. (1985). Communicative competence: Some roles of comprehensible input and comprehensible output in its development. In S. Gass \& C. Madden (Eds.), Input in second language acquisition (pp.235-253), Rowley, MA: Newbury House.

Vygotsky, L. S. (1978). Mind in society: The development of higher mental processes. Cambridge, MA: Harvard University Press.

Vygotsky, L. S. (1986). Thought and language. Cambridge, MA: The MIT Press.

Walsh, S. (2006). Investigating classroom discourse. London: Routledge.

Walsh, S. (2011). Exploring classroom discourse: Language in action. London: Routledge.

\section{Copyrights}

Copyright for this article is retained by the author(s), with first publication rights granted to the Journal.

This is an open-access article distributed under the terms and conditions of the Creative Commons Attribution license (CC BY-NC-ND) (http://creativecommons.org/licenses/by-nc-nd/4.0/). 